\title{
PATTERNS OF BACTERIAL RESISTANCE TO PENICILLIN, AUREOMYCIN, AND STREPTOMYCIN ${ }^{1}$
}

\author{
By M. DEMEREC \\ (From the Department of Genetics, Carnegie Institution of Washington, \\ Cold Spring Harbor, N. Y.)
}

During the last few years genetic research with bacteria has made significant progress, and ample evidence has accumulated to show that the hereditary mechanism operating in bacteria may be similar to that in higher organisms. It has been demonstrated that hereditary changes, comparable to mutations, occur in bacteria, and that these cover a range of types similar to those found in fungi, where genetic analysis is possible (1). Furthermore, an association resembling linkage in higher organisms has been observed in bacteria (2).

Experimental evidence indicates that changes in bacteria from sensitivity to resistance to penicillin and streptomycin originate as mutations, and that these antibiotics act only as selective agents which eliminate the sensitive bacteria and thus allow the resistant mutants, which are always present in any large population, to multiply (3). Experiments have revealed that the development of high resistance follows a definite pattern, which appears to be characteristic for each antibiotic and which is not determined by the bacteria involved. Detailed analyses of the pattern of streptomycin resistance have been made by me with Escherichia coli and Staphylococcus aureus, and by Dr. V. Bryson (unpublished) with Mycobacterium ranae. This work has revealed a remarkable similarity of behavior in these species of bacteria. Quantitative studies of penicillin resistance have been made only with Staphylococcus aureus $(4,5)$, but the results of other investigators, who have studied various phases of the action of penicillin with a wide variety of species, do not suggest that the pattern of resistance to penicillin is different in other bacteria from that analyzed with Staphylococcus.

At present two patterns of resistance have been established, the penicillin pattern and the streptomycin pattern. A "stepwise" development of re-

\footnotetext{
1 Presented at the Second National Symposium on Recent Advances in Antibiotics Research held in Washington, D. C., April 11-12, 1949, under the auspices of the Antibiotics Study Section, National Institutes of Health, Public Health Service, Federal Security Agency.
}

sistance is common to both, but they differ significantly in the manner in which high-level resistance is arrived at. In the case of penicillin, the firststep resistant mutants are very uniform in their degree of resistance, which is only slightly higher than that of the original strain. Additional mutations occurring in such first-step mutants result in bacteria possessing a higher (second-step) degree of resistance, and in a similar manner third-step and still higher resistance develops. Always the variation in degree of resistance among mutants of the same step is slight. This uniformity constitutes the most striking feature of the penicillin pattern; and it explains the stepwise increase in resistance. Because a significant degree of resistance can be attained only by additional mutation in an already mutant bacterium, at least two mutations in the same individual are required to bring it about. Since the mutation rate is low, however-about $1 \times 10^{-8}$ per bacterium per generation-the chances for simultaneous occurrence of such double mutations are extremely low $(1 \times$ $10^{-16}$, or practically nil), so that a large number of first-step resistant bacteria must first be present in order that a second-step mutant may occur. In other words, higher resistance may be attained only in successive steps, and no step may be skipped in this process.

The streptomycin pattern of resistance differs from the penicillin pattern in that the variation between first-step mutants is very great. They range from individuals only slightly more resistant than the original bacteria to those having complete resistance to streptomycin. Thus, although higher resistance may be attained in successive steps, as with penicillin, it may also arise in a first-step mutant.

I have attempted to analyze the resistance pattern for aureomycin, but this work has been complicated by the mode of action of that antibiotic on Escherichia coli, the organism used for the experiments. It was found that aureomycin, in addition to killing some of the bacteria, suppresses 
TABLE I

Per cent of bacteria appearing as colonies after certain incubation periods when plated in broth-agar containing various concentrations of aureomycin

\begin{tabular}{c|c|c|c|c|c}
\hline \hline $\begin{array}{c}\text { Concen- } \\
\text { tration } \\
\mu \mathrm{g} / \mathrm{ml}\end{array}$ & \multicolumn{5}{|c}{ Hours incubation } \\
\cline { 2 - 6 } & 24 & 72 & 96 & 120 & 144 \\
\hline & $\begin{array}{c}\text { Per cent } \\
\text { colonies }\end{array}$ & $\begin{array}{c}\text { Per cent } \\
\text { colonies }\end{array}$ & $\begin{array}{c}\text { Per cent } \\
\text { colonies }\end{array}$ & $\begin{array}{c}\text { Per cent } \\
\text { colonies }\end{array}$ & $\begin{array}{c}\text { Per cent } \\
\text { colonies }\end{array}$ \\
Control & 100 & & & & \\
1 & 0 & 75 & & & \\
5 & 0 & 0.12 & 70 & & \\
10 & 0 & 0 & 0.15 & 29 & \\
15 & 0 & 0 & 0 & 0 & 4.1 \\
20 & 0 & 0 & 0 & 0 & 3.5 \\
30 & 0 & 0 & 0 & 0 & 0.7 \\
\hline
\end{tabular}

division in the survivors. Since the aureomycin loses some of its potency during an experiment, these suppressed bacteria begin to divide again whenever the concentration of antibiotic on the plate is lowered to a certain point (Table I). If a large number of bacteria is plated, some will begin to grow earlier than others. In the anticipation that these might be more resistant to aureomycin, they were used to establish strains, which were tested for resistance; and from these a further selection of early growers was made. In this way strains that appeared to be more resistant to aureomycin were obtained. One such strain, obtained through five selections, when plated in broth-agar containing $10 \mu \mathrm{g}$ of aureomycin per $\mathrm{ml}$, gave 50 per cent survival, with colonies appearing after 48 hours of incubation. Under similar conditions, the original strain gave 29 per cent survival, the colonies appearing only after 120 hours of incubation.

These results show definitely that the pattern of aureomycin resistance is different from that of streptomycin resistance, in that highly resistant mutants do not appear in one step. It may be similar to the penicillin resistance pattern, but analysis to determine this has not been carried through because of complications introduced into the experiments by the loss of potency of aureomycin.

The genetic mechanism responsible for both the penicillin and the streptomycin resistance patterns may be explained by the assumption that several genes govern the reactions that determine sensitivity or resistance, and that the set of genes affecting penicillin resistance is different from the set of genes affecting streptomycin resistance. If any one of these genes should mutate, the bacterium in which such a mutation occurs and the strain developed from that bacterium will be more resistant to the respective antibiotic than was the original parent strain. Such a strain is what we have called a "first-step resistant strain."

The fact that first-step penicillin-resistant strains are fairly uniform in degree of resistance is consistent with the assumption that all genes affecting resistance to penicillin have a similar potency, so that the effect of mutation is the same regardless of which of the genes happens to mutate. According to this hypothesis, there is still present in a first-step resistant strain a number of unmutated genes that affect resistance. Mutation of any of these produces a second-step resistant strain, which possesses a higher degree of resistance than the first-step strain. Similarly, by mutation of another gene in a second-step resistant strain, a still higher degree of resistance is attained, characteristic of the third-step resistant strain; and by further repetition of the process a very high degree of resistance may be reached.

The observed behavior of resistance to streptomycin also can be explained by assuming the existence of several genes determining such resistance. Unlike the genes for penicillin resistance, however, these differ greatly from one another in potency. If a gene of low potency mutates, the first-step resistant strain will have a low degree of resistance, but if mutation occurs in a highly potent gene, the first-step resistant strain will be highly resistant. Consequently, considerable variation in degree of resistance is to be expected between first-step strains; and for the same reason a highly resistant strain may be obtained either in one step, by selection of a highly resistant firststep mutant, or in several steps, by selection of mutants of low resistance values.

The assumption that several genes are responsible for resistance is not unusual; a similar assumption, involving the presence of about 20 genes, has already been made to explain the complex situation observed in a study of resistance of $E$. coli to several bacteriophages (6). Also, experiments now under way in my laboratory indicate that several genes are involved in changes of $E$. coli from streptomycin sensitivity to strepto- 
mycin resistance and dependence, as well as in reversions from dependence to sensitivity.

\section{BIBLIOGRAPHY}

1. Tatum, E. L., X-ray induced mutant strains of Escherichic coli. Proc. Nat. Acad. Sc., 1945, 31, 215.

2. Lederberg, J., Gene recombination and linked segregations in Escherichia coli. Genetics, 1947, 32, 505.

3. Demerec, M., Origin of bacterial resistance to antibiotics. J. Bact., 1948, 56, 63.
4. Demerec, M., Production of staphylococcus strains resistant to various concentrations of penicillin. Proc. Nat. Acad. Sc., 1945, 31, 16.

5. Demerec, M., Genetic aspects of changes in Staphylococcus aureus producing strains resistant to various concentrations of penicillin. Ann. Missouri Bot. Garden, 1945, 32, 131.

6. Demerec, M., and Fano, U., Bacteriophage-resistant mutants in Escherichia coli. Genetics, 1945, 30, 119. 